\title{
Efisiensi pemeliharaan taman: studi kasus di hotel the Oberoi, Bali
}

\author{
I Nyoman Darma Pranata ${ }^{1}$, Anak Agung Gede Dalem Sudarsana ${ }^{1 *}$, Ni Nyoman Ari Mayadewi ${ }^{2}$
}

1. Program Studi Arsitektur Pertamanan, Fakultas Pertanian, Universitas Udayana, Indonesia 80114

2. Progam Studi Agroekoteknologi, Fakultas Pertanian, Universitas Udayana, Indonesia 80114

*E-mail:agungdalems@gmail.com

\begin{abstract}
Gardening efficiency: case study in the Oberoi Hotel, Bali. Bali is one of the very famous international tour destination around the world. One important element of tourism is accommodation as a rest area. Hotel The Oberoi Bali is one of the five stars hotel as accommodations in Bali. Hotel The Oberoi Bali has six hectare land with $60 \%$ of outdoor area and $40 \%$ of building area. This study aims to find the efficiency of the park keepers in Hotel The Oberoi Bali. The method that used in this study is survey method, with observation techniques interview, literature review and questionnaire. Based on the result of the research, it is found that the maintenance system which is applied is the maintenance system of the unit or zone, and the special maintenance system, the work capacity is done on sweeping or paving and grass pruning with thrust machine, less work in watering activities using sprinklers and plastic hoses, pruning bushes and ground cover with pruned shears. Recommendation of maintenance schedule in writing, reward system for garden staff to improve work efficiency and training which can increase knowledge and skill in maintenance activities for labor.
\end{abstract}

Keywords: gardening efficiency, hotel the Oberoi Bali, work capacity

\section{Pendahuluan}

\section{$1.1 \quad$ Latar Belakang}

Bali merupakan salah satu daerah tujuan wisata internasional yang sangat terkenal di dunia. Sektor kepariwisataan telah menjadi penggerak perekonomian dan pembangunan di Bali sejak tahun 1970-an, oleh karena itu kepariwisataan merupakan bagian yang sangat erat dan tidak dapat dipisahkan lagi dalam kehidupan masyarakat dan pembangunan di Bali (Pitana, 2002). Jumlah kunjungan yang bertambah secara signifikan dari tahun ke tahun membuat Bali sebagai salah satu destinasi wisata favorit bagi wisatawan lokal maupun wisatawan mancanegara. Keindahan pulau Bali, keragaman suku dan budaya, keramahtamahan masyarakatnya adalah beberapa faktor yang menunjang Bali sebagai salah satu destinasi wisata favorit. Salah satu unsur terpenting pariwisata adalah sarana akomodasi sebagai tempat menginap atau beristirahat. Salah satu contoh akomodasi yang diperlukan oleh wisatawan adalah hotel.

Hotel bintang lima dituntut untuk menyajikan hardscape (elemen keras) dan softscape (elemen lunak/vegetasi) yang memiliki kualitas tinggi. Eckbo (1964) menyatakan bahwa lansekap merupakan ruang di sekeliling manusia yang mencakup segala sesatu yang dapat dilihat dan dirasakan serta merupakan pengalaman terus menerus sepanjang waktu dan seluruh ruang kehidupan manusia. Lansekap sebuah hotel dapat meningkatkan nilai keindahan hotel tersebut, untuk menjaga keindahan lansekap maka diperlukannya pemeliharaan lansekap agar keindahan dan kenyamanan lanskap tersebut terjaga dengan baik.

Pemeliharan lansekap dibagi menjadi dua pemeliharaan ideal dan pemeliharaan fisik. Pemeliharaan ideal adalah pemeliharaan yang bertujuan untuk mempertahankan keadaan tapak agar sesuai dengan desain semula, sedangkan pemeliharaan fisik meliputi penyiraman, pengendalian hama \& penyakit, pemangkasan, pengurasan, penyapuan, dan lain-lain (Rachman, 1984). Pemeliharaan lanskap memerlukan tenaga kerja untuk menjalankannya. Tenaga kerja sangat berperan dalam pemeliharaan lanskap, jika pemeliharaan lanskap itu berjalan baik maka pemeliharaan lanskap itu didukung dengan tenaga kerja yang bekerja dengan baik, begitu juga sebaliknya.

Menurut UU Pokok Ketenagakerjaan No. 14 Tahun 1969, tenaga kerja (SDM) adalah setiap orang yang mampu melakukan pekerjaan baik di dalam maupun di luar hubungan kerja guna menghasilkan barang 
atau jasa untuk memenuhi kebutuhan masyarakat. Kemampuan dan keterampilan tenaga kerja sangat dibutuhkan agar pemeliharaan dapat berjalan dengan maksimal. Efektivitas kerja menurut Sternloff dan Warren (1984) sangat ditentukan oleh motivasi kerja dan tingkat keterampilan yang di miliki oleh pekerja, sistematika jadwal perencanaan pemeliharaan, ketersediaan alat dan bahan yang sesuai dengan kebutuhan, tingkat pengawasan kerja di lapangan, dan kelancaran komunikasi antara pimpinan dan pegawai.

Hotel The Oberoi Bali adalah salah satu hotel bintang lima yang menjadi akomodasi yang terdapat di pulau Bali. Hotel ini terletak di Jalan Kayu Aya, Kuta Utara, Badung Bali. Hotel The Oberoi Bali memiliki lahan seluas enam hektar dengan persentase ruang terbuka sebanyak $60 \%$ dan persentase bangunan sebanyak $40 \%$. Persentase ruang terbuka yang lebih dominan dibadingkan dengan bangunan mengharuskan pihak hotel untuk melakukan pemeliharaan taman agar kenyamanan serta keindahan taman tetap terjaga dan selalu menyediakan pelayanan yang berkualitas tinggi bagi pengguna jasanya. Kepuasan pengunjung yang menjadi tujuan utama dalam manajemen hotel sangat didukung oleh upaya pengelolaan lansekap yang baik, khususnya dalam aspek pemeliharaan lansekap, sehingga upaya pemeliharaan taman sangat penting perannya karena taman merupakan bagian dari citra yang ditampilkan Hotel The Oberoi Bali.

Penelitian ini bertujuan untuk menilai tingkat efisensi tenaga kerja (SDM) pemeliharaan taman di Hotel The Oberoi Bali serta menghasilkan kapasitas kerja pekerja taman Hotel The Oberoi. Penelitian ini menggunakan metode survei dengan teknik pengumpulan data, menggunakan teknik observasi dan wawancara serta menggunakan kuisoner untuk membantu mendapatkan data pemeliharaan taman.

\section{Metode Penelitian}

\subsection{Tempat dan Waktu Penelitian}

Penelitian ini dilaksanakan di Hotel The Oberoi Bali yang terletak di Jalan Kayu Aya, Kecamatan Kuta Utara, Kabupaten Badung, Provinsi Bali dan dilakukan dari Bulan Februari sampai bulan juni 2017.

\subsection{Alat Penelitian}

Alat yang digunakan dalam penelitian ini adalah kamera, laptop dengan software Google Maps, AutoCAD 2013 dan Adobe Photoshop CS4, dan lembar kuisioner.

\subsection{Data Penelitian}

\subsubsection{Jenis Data}

Jenis data yang didapat dalam penelitian ini terdapat dua jenis, yaitu data primer dan data sekunder. Data primer merupakan data yang diperoleh langsung di lapang. Data sekunder merupakan studi pustaka mengenai teori pemeliharaan taman yang efisien dari para ahli.

Tabel 1 Jenis Data Inventarisasi

\begin{tabular}{|c|c|c|c|}
\hline No & Jenis & Sumber & Pengambilan data \\
\hline $\begin{array}{l}2 . \\
3 .\end{array}$ & $\begin{array}{l}\text { Aspek Biofisik } \\
\text { - Letak dan Luas } \\
\text { - Iklim } \\
\text { - Hidrologi } \\
\text { - Vegetasi dan Satwa } \\
\text { Aspek Sosial } \\
\text { - Struktur Organisasi } \\
\text { Pemeliharaan Lansekap } \\
\text { - Konsep Pemeliharaan } \\
\text { - Biaya } \\
\text { - Pelaksanaan Pemeliharaan } \\
\text { - Tenaga Kerja } \\
\text { - Wilayah kerja } \\
\text { - Alat dan Bahan } \\
\end{array}$ & $\begin{array}{l}\text { Lapangan } \\
\text { BMKG } \\
\text { Lapangan } \\
\text { Lapangan } \\
\text { The Oberoi Bali } \\
\text { Lapangan } \\
\text { Lapangan } \\
\text { Lapangan } \\
\text { Lapangan } \\
\text { Lapangan } \\
\text { Lapangan }\end{array}$ & $\begin{array}{l}\text { Studi pustaka } \\
\text { Studi pustaka } \\
\text { Wawancara, survei } \\
\text { Survei, wawancara, studi pustaka } \\
\text { Studi pustaka, wawancara } \\
\text { Wawancara, studi pustaka } \\
\text { Wawancara } \\
\text { Pengamatan } \\
\text { Wawancara, pelaksanaan } \\
\text { Pengamatan, pelaksanaan } \\
\text { Wawancara, survei }\end{array}$ \\
\hline
\end{tabular}

Menurut Arifin dan Arifin (2005) yang dijadikan acuan kapasitas kerja pemeliharaan taman seperti pada tabel berikut : 
Tabel. 2 Kapasitas kerja operator pemeliharaan taman

\begin{tabular}{llc}
\hline No & \multicolumn{1}{c}{ Jenis Pemeliharaan Taman } & Kapasitas Kerja/jam \\
\hline 1. & Pembersihan/penyapuan rumput & $400 \mathrm{~m}^{2}$ \\
2. & Pembersihan/penyapuan perkerasan & $800 \mathrm{~m}^{2}$ \\
3. & Penyiraman rumput dengan sprinkler & $500 \mathrm{~m}^{2}$ \\
4. & Penyiraman rumput dan tanaman penutup tanah dengan selang & $150 \mathrm{~m}^{2}$ \\
& plastik3/4 & 15 pohon \\
5. & Penyiraman pohon dengan selang plastic 3/4 & $500 \mathrm{~m}^{2}$ \\
6. & Pemangkasan rumput dengan mesin dorong rover & $10 \mathrm{~m}^{2}$ \\
7. & Pemangkasan tanaman semak dan penutup tanah dengan gunting & \\
\hline
\end{tabular}

\subsubsection{Metode Penelitian}

Metode penelitian yang digunakan dalam penelitian ini adalah metode survei dengan teknik pengumpulan data yang digunakan dalam penelitian ini adalah dengan cara observasi, wawancara, penyebaran kuisioner dan studi pustaka:

1. Observasi.

Observasi merupakan teknik pengumpulan data melalui pengamatan langsung di lapangan untuk memperoleh gambaran mengenai aspek biofisik dan aspek pemeliharaan lanskap pada kawasan Hotel The Oberoi Bali.

2. Wawancara.

Wawancara merupakan teknik pengumpulan data yang digunakan untuk memperoleh informasi dengan mengadakan tanya jawab langsung terhadap housekeeping manager dan supervisor Hotel The Oberoi Bali.

3. Penyebaran Kuisioner.

Kuisioner yang digunakan adalah kuisioner tertutup. Teknik sampling yang digunakan adalah purposive sampling yaitu teknik penentuan sampel yang sengaja dipilih peneliti berdasarkan pertimbangan tujuan penelitian melalui pertanyaan yang diajukan mengenai pemeliharaan taman Hotel The Oberoi Bali. Kuisioner ditunjukkan kepada para pekerja taman (gardener) dengan tujuan untuk mencari informasi tambahan mengenai pemeliharaan taman yang di lakukan di Hotel The Oberoi Bali.

4. Studi Pustaka:

Studi kepustakaan adalah teknik pengumpulan data yang berhubungan dengan penelitian ini seperti buku Pemeliharaan Taman (Hadi Susilo Arifin Nurhayati), Keadaan Meteorologi dan Geofisika Pulau Bali menurut Kabupaten atau Kota 2014 (BPS Provinsi Bali 2016), UU No 14 Tahun 1969 Tentang Tenaga Kerja (http://www.hukumonline.com).

\subsubsection{Analisis Data}

1. Tabulasi

Menurut Sudjana (2001), teknik tabulasi data ini digunakan untuk menghitung jumlah pilihan responden (f) dibandingkan dengan jumlah keseluruhan responden (N) ke dalam bentuk presentase (\%) dengan dikali 100 persen, dengan persamaan sebagai berikut:

Keterangan:

$$
P=f / N \times 100 \%
$$

$\mathrm{P}=$ Presentase

$\mathrm{F}=$ Frekuensi

$\mathrm{N}=\sum$ Total Responden

2. Analisis Deskriptif

Analisis deskriptif digunakan untuk menganalisis data dengan cara mendeskripsikan atau menggambarkan data yang telah terkumpul tanpa bermaksud membuat kesimpulan yang berlaku untuk umum. Hal ini sesuai dengan rumusan yang ditentukan oleh Sugiyono (2004). 


\subsection{Batasan Penelitian}

Penelitian ini dibatasi pada aspek kegiatan pemeliharaan lansekap pada kawasan Hotel The Oberoi Bali yang meliputi kegiatan menyapu, menyiram, penyiangan, pemupukan, pendangiran, pemeliharaan hardscape, pemangkasan, pengendalian hama dan penyakit.

\section{Hasil dan Pembahasan}

\subsection{Gambaran Umum}

\subsubsection{Letak dan luas}

Hotel The Oberoi Bali terletak di pantai Seminyak Jalan Kayu Aya, Badung, Bali. Terletak di pantai yang indah di pulau ini, di tengah taman lansekap seluas enam hektar. Fasilitas yang terdapat di hotel ini adalah kolam renang, spa, gym, restaurant, bar dan lapangan tenis.

\subsubsection{I $\mathrm{klim}$}

Keadaan Meteorologi dan Geofisika Pulau Bali menurut Kabupaten atau Kota 2014 menunjukkan suhu rata-rata Kabupaten Badung tahun 2014 adalah 27,40 C cukup tinggi jika dibandingkan dengan suhu kabupaten lainnya. Rata-rata kelembaban udara yaitu $79 \%$ dengan rata-rata curah hujan $1.640,6 \mathrm{~mm}$ per tahun.

\subsubsection{Hidrologi}

Hasil wawancara dengan Ibu Kadek Ari Parwati yang menjabat sebagai Front Office Manager mengatakan bahwa pengairan untuk taman, didapat dari air yang di tamping di ground tank.

\subsubsection{Biaya}

Penghasilan yang didapatkan oleh gardener Hotel The Oberoi Bali sesuai dengan UMR Kabupaten Badung. Biaya yang dikeluarkan oleh pihak The Oberoi Bali untuk membiayai upah gardener setiap bulannya adalah Rp 61.224.490.

\subsubsection{Stuktur Organisasi}

Pengelolaan dan pemeliharaan taman pada kawasan Hotel The Oberoi Bali, ini dipimpin oleh seorang supervisor dan executive housekeeper di bawah naungan dari executive assistant manager-rooms Hotel The Oberoi Bali.

\subsubsection{Sistem Pemeliharaan}

Dalam pelaksanaan pemeliharaan lansekap, pihak pengelola menerapkan sistem pemeliharaan secara semi kontrak, yaitu seluruh pekerjaan pemeliharaan diserahkan dan dikerjakan oleh kontraktor, namun alat dan bahan yang digunakan untuk kegiatan pemeliharaan taman sepenuhnya ditanggung oleh pihak hotel. Sistem yang diterapkan oleh pihak kontrakor adalah sistem pemeliharaan unit atau zona dan sistem pemeliharaan khusus. Sistem pemeliharaan unit yaitu pemeliharaan yang didasarkan pada unit-unit atau zona taman yang ada, sehingga setiap unit atau zona taman mempunyai tim pemeliharaan sendiri. Sistem tim pemeliharaan khusus yaitu pemeliharaan didasar pada keahlian tertentu dari pegawainya (memangkas menggunakan mesin dorong rover, dan memangkas pohon)

\subsection{Hasil dan Pembahasan}

\subsubsection{Vegetasi}

Hotel The Oberoi Bali, memiliki berbagai macam jenis vegetasi yang setiap vegetasi memiliki fungsi dan peranannya masing-masing. Jumlah pohon yang berada di Hotel The Oberoi Bali adalah sebanyak 969 pohon, jumlah semak seluas $1.430 \mathrm{~m}^{2}$, jumlah tanaman perdu sebanyak 1.062 buah dan jumlah tanaman rumput seluas $6.754 \mathrm{~m}^{2}$.

\subsubsection{Tenaga Kerja}

Pihak kontraktor yang berkerjasama dengan pihak Hotel The Oberoi Bali memiliki 24 gardener (pekerja taman) dan satu supervisor yang disebar di beberapa block (area pemeliharaan) di Hotel The Oberoi Bali. Pihak kontraktor membagi wilayah kerja pekerja taman menjadi 10 area pemeliharaan, 10 area pemeliharaan memiliki luas yang tidak sama dan beberapa pekerja taman mempunyai tugas untuk membantu seluruh areal dalam melaksanakan pemeliharaan taman.

Kendala yang ditemui adalah adanya pekerja taman yang bekerja kurang optimal, hal ini disebabkan oleh beberapa faktor: kurangnya pelatihan pemeliharaan untuk pekerja taman, kurangnya motivasi bekerja dan penghargaan untuk dedikasi pekerjaan yang telah dilakukan,. Sebaiknya dilakukan sebuah sistem penghargaan agar meningkatkkan motivasi dan semangat bekerja. 


\subsubsection{Konsep Pemeliharaan}

Konsep pemeliharaan yang diterapkan oleh pihak Hotel The Oberoi Bali adalah konsep pemeliharaan ideal dan pemeliharaan fisik. Pemeliharaan ideal pada Hotel The Oberoi Bali bertujuan untuk memelihara kawasan hotel agar tetap sesuai dengan tujuan awal seperti menerapkan konsep taman Balinese Tropical Garden. Pemeliharaan fisik yang dilakukan berperan penting agar konsep taman tersebut bertahan dengan baik dapat dilihat dari kegiatan pemeliharaan yang sehari-hari dilakukan oleh gardener Hotel The Oberoi Bali.

\subsubsection{Kapasitas Kerja}

Arifin \& Arifin (2005) menjelaskan bahwa efektifitas kerja operator taman menentukan efisiensi biaya pemeliharaan taman, selanjutnya dijelaskan bahwa efektifitas kerja pemeliharaan taman ditentukan oleh beberapa hal seperti motivasi kerja dan tingkat ketrampilan pekerja, sistematika jadwal pemeliharaan taman, ketersediaan alat dan bahan, dan tingkat pengawasan di lapang.

Kapasitas kerja yang dimiliki oleh gardener Hotel The Oberoi Bali diperoleh berdasarkan hasil pengamatan yang dilakukan di lapangan (Tabel 3). Nilai kapasitas kerja pekerja taman hotel dibandingkan dengan nilai kapasitas kerja Arifin dan Arifin (2005).

Tabel 3 Kapasitas Kerja gardener Hotel The Oberoi Bali.

\begin{tabular}{lllll}
\hline No & Jenis Pemeliharaan Taman & $\begin{array}{l}\text { Standar Kapasitas } \\
\text { Kerjaljam (a) }\end{array}$ & $\begin{array}{l}\text { Kapasitas } \\
\text { Kerja/jam(b) }\end{array}$ & Realisasi \\
\hline 1. & Pembersihan/penyapuan rumput & $400 \mathrm{~m}^{2}$ & $526 \mathrm{~m}^{2}$ & $131,5 \%$ \\
2. & Pembersihan/penyapuan perkerasan & $800 \mathrm{~m}^{2}$ & $972 \mathrm{~m}^{2}$ & $121,5 \%$ \\
3 & Penyiraman rumput dengan sprinkler & $500 \mathrm{~m}^{2}$ & $407 \mathrm{~m}^{2}$ & $81,4 \%$ \\
4 & $\begin{array}{l}\text { Penyiraman rumput dan tanaman } \\
\text { penutup tanah dengan selang plastik }\end{array}$ & $150 \mathrm{~m}^{2}$ & $107 \mathrm{~m}^{2}$ & $71,3 \%$ \\
5 & $\begin{array}{l}\text { Penyiraman pohon dengan selang } \\
\text { plastic }\end{array}$ & 15 pohon & 13 pohon & $86,6 \%$ \\
6 & $\begin{array}{l}\text { Pemangkasan rumput dengan mesin } \\
\text { dorong }\end{array}$ & $500 \mathrm{~m}^{2}$ & $530 \mathrm{~m}^{2}$ & $106 \%$ \\
7 & $\begin{array}{l}\text { Pemangkasan tamanan semak dan } \\
\text { penutup tanah dengan gunting pangkas }\end{array}$ & $10 \mathrm{~m}^{2}$ & $4.8 \mathrm{~m}^{2}$ & $48 \%$ \\
\hline
\end{tabular}

(a) : Kapasitas kerja Arifin dan Arifin (2005)

(b) : Kapasitas kerja pekerja taman Hotel The Oberoi Bali

Hasil pengamatan yang tercantum pada Tabel 3.1 dapat dilihat adanya perbedaan antara kapasitas kerja Hotel The Oberoi Bali dengan yang diperoleh dari Arifin dan Arifin (2005).

\subsubsection{Pelaksanaan Pemeliharaan}

Pelaksanaan pemeliharaan yang rutin dilakukan oleh pihak gardener Hotel The Oberoi Bali berupa pemeliharaan fisik dan dikerjakan tanpa adanya SOP (standar operational) yang tertulis seperti penyapuan, pemangkasan, penyiraman, dll.

\subsubsection{Penyapuan}

Kegiatan penyapuan di Hotel The Oberoi Bali di bagi menjadi dua, penyapuan perkerasan dan penyapuan rumput. Kapasitas kerja pekerja taman dalam kegiatan penyapuan rumput adalah sebesar $526 \mathrm{~m}^{2} / \mathrm{jam}$ lebih besar 31,5\% dari kapasitas kerja ideal, sedangkan kapasitas kerja dari kegiatan penyapuan perkerasan adalah sebesar 972 m²/jam lebih besar 21,5\% dari kapasitas kerja ideal. Hal ini disebabkan oleh sistem pemeliharaan unit yang di terapkan oleh pihak kontraktor. Sistem pemeliharaan ini menempatkan dua gardener bekerja pada satu zona secara terus menerus dan hal ini mengakibatkan gardener lebih mengenal zona tersebut, serta komunikasi antar gardener berjalan dengan lebih baik sehingga menyebabkan kegiatan ini lebih besar dari kapasitas kerja ideal atau milik Arifin dan Arifin (2005). 


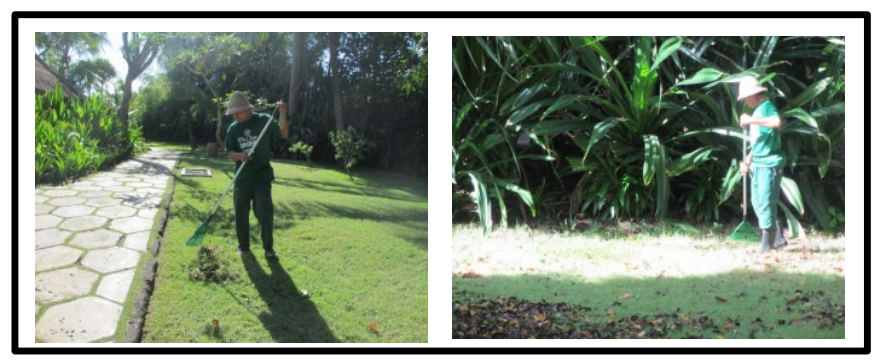

Gambar 2. Penyapuan atau pembersihan rumput

\subsubsection{Penyiraman}

Penyiraman di Hotel The Oberoi Bali menggunakan dua cara yaitu cara manual (selang plastik) dan menggunakan bantuan alat (sprinkler). Kapasitas kerja dari kegiatan penyiraman rumput menggunakan sprinkler adalah sebesar $407 \mathrm{~m}^{2} / \mathrm{jam}$ lebih rendah $18,6 \%$ dari kapasitas kerja ideal. Hal ini disebabkan karena pekerja taman hotel terlalu lama memindahkan sprinkler dari satu areal ke areal lainnya, dan hal lainnya disebabkan karena kegiatan ini dilakukan serempak dengan kegiatan penyapuan/pembersihan perkerasan dan rumput menyebabkan pekerja taman lebih fokus dalam melaksanakan kegiatan pembersihan dan penyapuan rumput.

Kapasitas kerja pekerja taman Hotel The Oberoi Bali dalam pelaksanaan kegiatan penyiraman rumput dan tanaman penutup tanah dengan menggunakan selang plastik ini adalah sebesar $107 \mathrm{~m}^{2} / \mathrm{jam}$ kegiatan ini lebih rendah 28,6\% dari kapasitas kerja ideal. Hal ini disebabkan karena kegiatan ini dilakukan seiringan dengan kegiatan penyiraman pohon menggunakan selang plastik sehingga menyebabkan pekerja taman melakukan kegiatan ini secara tidak optimal dan kegiatan ini dilakukan ketika ingin menggulung selang serta menutup kran air.

Kapasitas kerja pekerja taman Hotel The Obero Bali dalam pelaksanaan kegiatan penyiraman pohon dengan menggunakan selang plastik ini adalah sebesar 13 pohon/jam kegiatan kurang efisien 13,3\% jika dibandingkan dengan kapasitas kerja ideal. Hal ini disebabkan karena kegiatan ini dilakukan bersamaan dengan kegiatan penyiraman rumput dan tanaman penutup tanah dengan menggunakan selang plastik, hal lainnya disebabkan karena faktor jarak pohon yang berjauhan.

Sebaiknya dibuatkan semacam jadwal pemeliharaan yang tertulis agar kegiatan penyiraman ini berjalan lebih baik lagi atau dibuatkan sebuah sistem penghargaan untuk pekerja taman yang bekerja secara optimal dan memiliki kapasitas kerja lebih baik dari kapasitas kerja ideal sedangkan untuk pekerja taman yang bekerja kurang dari kapasitas kerja ideal sebaiknya diberikan peringatan atau sanksi agar pekerja taman bekerja lebih optimal.

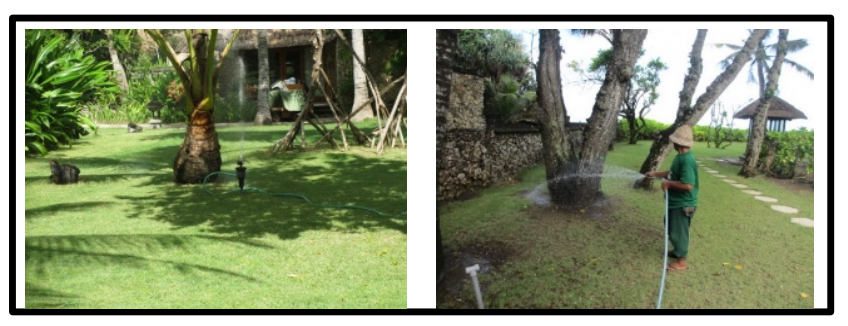

a. Penyiraman Menggunakan Sprinkler b. Penyiraman Menggunakan Selang Gambar 3 Kegiatan Penyiraman Taman

\subsubsection{Pemangkasan}

Pemangkasan tanaman penutup tanah, semak dan perdu lebih difokuskan sebagai penambah nilai estetika. Kegiatan pemotongan rumput dengan menggunakan mesin dorong rover dilakukan lebih dari empat kali dalam sebulan, kapasitas kerja pekerja taman Hotel The Oberoi bali dalam kegiatan ini sebesar $530 \mathrm{~m}^{2} / \mathrm{jam}$ lebih efisien $6 \%$ jika dibandingkan dengan kapasitas kerja ideal. Hal ini disebabkan karena kegiatan ini dilakukan dengan pekerja taman yang berusia muda dan pekerja taman tersebut hanya mempunyai satu tugas pokok yaitu pemotongan rumput menggunakan mesin dorong rover 
Kapasitas kerja dari kegiatan pemangkasan tanaman semak dan penutup tanah menggunakan gunting pangkas adalah sebesar $4,8 \mathrm{~m}^{2}$ ljam lebih rendah $52 \%$ jika dibandingkan dengan literatur yang digunakan. Hal ini diakibatkan karena kegiatan ini dilakukan setiap hari tepatnya pada siang hari, kegiatan ini dilakukan dengan santai dan kegiatan ini dilakukan untuk mengisi waktu menunggu jam pulang. Sebaiknya diberlakukan sistem penghargaan dan sanksi untuk meningkatkan motivasi dan disiplin kerja.

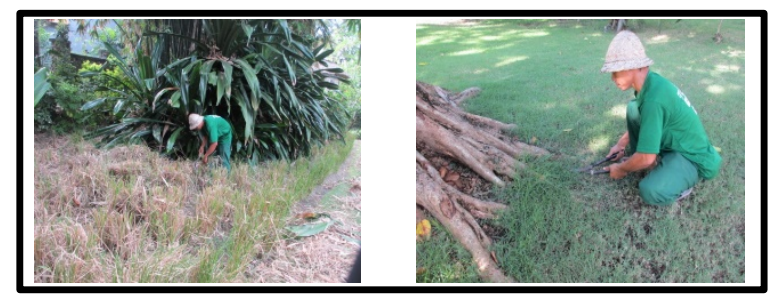

a. Pemangkasan Sema b. Pemangkasan Rumput

Gambar 4 Pemangkasan

\subsubsection{Pendangiran dan penyiangan gulma}

Kegiatan pendangiran dan penyiangan gulma dilakukan setiap hari oleh pekerja taman agar pertumbuhan dan perkembangan tanaman tidak terganggu. Kegiatan ini dilakukan setelah kegiatan pemangkasan semak dan perdu agar tanaman terkesan lebih rapi dan indah. Kegiatan pendangiran dilakukan menggunakan bantuan alat kored, sedangkan kegiatan penyiangan gulma dilakukan dengan cara manual. Pendangiran atau penggemburan tanah yang dilakukan sudah cukup baik, namun waktu pelaksanaannya kadang kurang diperhatikan. Pekerja taman melakukan penggemburan pada waktu siang hari. Menurut Arifin dan Nurhayati (2000) penggemburan sebaiknya tidak dilakukan pada musim kemarau atau pada saat terik matahari karena dapat mempercepat laju evaporasi sehingga tanaman menjadi stres.

Sebaiknya kegiatan pendangiran dan pengemburan tanah dilakukan pada pagi hari, jika kegiatan ini dilakukan pada siang hari maka akan menyebabkan tanaman menjadi stress. Kegiatan penyiangan terhadap gulma di Hotel The Oberoi Bali masih bisa di tangani dengan baik oleh pekerja taman.

\subsubsection{Pengendalian Hama dan Penyakit}

Pengendalian hama dan penyakit dilaksanakan secara tidak rutin. Hama yang sering menyerang tanaman adalah ulat bulu yang menyerang kembang sepatu (Hibiscus rosasinensis), hama kutu daun atau kutu putih (Coccus viridis) yang menyerang tunas baru dan menyebabkan penyakit embun jelaga. Tanaman yang terserang hama dan penyakit harus segera ditanggulangi karena dapat menyerang tanaman lain.Sebaiknya dibuatkan jadwal pemeliharaan secara tertulis dan dalam jadwal pemeliharan itu mencatumkan kegiatan pengendalian hama dan penyakit agar kegiatan ini dilakukan secara rutin.

\subsubsection{Pemupukan}

Kegiatan pemupukan pada Hotel The Oberoi Bali dilakukan secara tidak rutin, pemupukan dilakukan ketika melakukan kegiatan penanaman tanaman. Meskipun pemupukan di lakukan secara tidak menentu, tanaman pada Hotel The Oberoi Bali tidak menunjukkan penurunan dari kualitas jika di lihat melalui segi visualnya.

\subsubsection{Pemeliharaan Hardscape taman}

Pemeliharaan hardscape taman pada Hotel The Oberoi Bali sudah berjalan dengan baik, pekerja taman dapat menjaga kebersihan dan kualitas dari ornamen taman seperti kolam ikan, patung, jalan dan lampu taman.

\section{Simpulan dan Saran}

4.1 Simpulan

1. Efisiensi pemeliharaan taman di Hotel The Oberoi Bali tergolong cukup efisien ditinjau dari kapasitas kerja pemeliharaan taman dan dari biaya yang dikeluarkan.

2. Efisiensi kapasitas kerja yang melebihi kapasitas kerja ideal yaitu kegiatan penyapuan rumput (131\%), kegiatan penyapuan perkerasan (121\%) dan pemangkasan rumput menggunakan mesin dorong (106\%). Sedangkan kapasitas kerja yang kurang adalah kegiatan penyiraman rumput dengan sprinkler 
(81\%), penyiraman rumput dan tanaman penutup tanah dengan selang plastik (71\%), penyiraman pohon dengan selang plastik (86\%) dan pemangkasan semak dan penutup tanah dengan gunting pangkas (48\%).

3. Sistem pemeliharaan yang diterapkan oleh Hotel The Oberoi Bali adalah sistem semi kontrak, pihak kontraktor menyiapkan tenaga kerja pemeliharaan taman sedangkan pihak hotel menyiapkan alat pemeliharaan taman.

4. Konsep pemeliharaan yang di terapkan oleh Hotel The Oberoi Bali sudah sangat baik, konsep pemeliharan yang di terapkan adalah konsep pemeliharaan ideal dan pemeliharaan fisik.

5. Pemeliharaan yang diterapkan oleh Hotel The Oberoi Bali adalah pemeliharaan unit (unit maintenance), namun pihak Hotel The Oberoi Bali belum memiliki rencana dan jadwal pemeliharaan secara tertulis.

4.2 Saran

1. Perlu dibuatkan jadwal pemeliharaan secara tertulis agar pekerjaan dilapang dapat dilakukan dengan lebih baik.dan efisien.

2. Perlu diberlakukan sistem penghargaan dan sanksi bagi pekerja taman untuk meningkatkan motivasi kerja dan disiplin kerja, pengoptimalan dalam penggunaan sumber daya serta menciptakan koordinasi yang harmonis antar pihak untuk meningkatkan efektifitas dan efisiensi kerja.

\section{Daftar Pustaka}

Arifin, H. S.dan Nurhayati. 2000. Pemeliharaan Taman. Penebar Swadaya, Jakarta. 192 hal.

Arifin, H.S. \& N.H.S. Arifin. 2005. Pemeliharaan Taman (Edisi Revisi). Penebar Swadaya, Jakarta. 171h.

Badan Pusat Statistik Provinsi Bali. 2016. Keadaan Meteorologi dan Geofisika Pulau Bali Menurut

Kabupaten/Kota Tahun 2013. https://bali.bps.go.id/linkTabelStatis/view/id/10. Diakses pada tanggal 20 Juli 2017

Eckbo, G. 1964. Urban Landscape Design. McGraw-Hill Book Co., New York. 284h.

Pitana, I.G., 2002, Pariwisata, Wahana Pelestarian Kebudayaan dan Dinamika Masyarakat Bali, Denpasar: Universitas Udayana

Rachman, Z. 1984. Proses Berpikir Lengkap Merencana \& Melaksana dalam Arsitektur Lanskap. Makalah Diskusi pada Festival Tanaman VI Himagron IPB. Bogor. Tidak dipublikasikan. 20h.

Sternloff, R.E. \& R. Warren. 1984. Park and Recreation Maintenance Management. John Wiley \& Sons Inc., New York. 326h.

Sudjana, D. 2001. Metode Statistika. Tarsito. Bandung.

Sugiyono, D. 2004. Metode Penelitian Bisnis. CV. Alfabeta. Bandung.

Undang-Undang Republik Indonesia Nomor 14 Tahun 1969 Tentang Ketentuan-Ketentuan Pokok Mengenai Tenaga Kerja. http://www.hukumonline.com. Diakses pada tanggal 21 Juli 2017 